\title{
Evaluasi Implementasi Radiology Information System Picture Archiving And Communication System (RISPACS) dengan Pendekatan Model HOT-FIT
}

\author{
Suandari, P.V.L a $^{\mathrm{a}^{*}}$, Kusworo Adi ${ }^{\mathrm{b}}$, Chriswardani Suryawati ${ }^{\mathrm{c}}$ \\ ${ }^{a}$ Institut Ilmu Kesehatan Medika Persada Bali \\ bFakultas Sains dan Matematika, Universitas Diponegoro \\ cMagister Ilmu Kesehatan Masyarakat, Fakultas Kesehatan Masyarakat Universitas Diponegoro \\ Naskah Diterima : 4 April 2019; Diterima Publikasi : 30 April 2019 \\ DOI : 10.21456/vol9iss1pp55-62
}

\begin{abstract}
The application of current technology such as the Radiology Information System Picture Archiving and Communication System (RISPACS) in radiology that doesn't meet the user's expectation can raise the inconvenience and affect their productivity. To anticipate this, it is important to understand the basic factors that contribute to the reception and successfulness of applicating RISPACS. This study aims to describe the evaluation of the successful implementation of RISPACS using the Human Organization Technology (HOT FIT) model approach in Radiology Installation at Sanglah Hospital Denpasar. The data in this research were analyzed by Partial Least Square (PLS) test and measuring 71 radiologists as respondents who use RISPACS. The evaluation results of the Human Organization Technology (HOT FIT) model show that the successful implementation of RISPACS technology has a positive assessment that is seen from the user's attitude in responding to a RISPACS technology that is felt to be in accordance with the expectations and operational needs of the user. Variable of system quality, information quality, service quality have a positive influence on system user variable and user satisfaction. While the variable of system users, user satisfaction, organizational structure, and organizational environment had a positive and significant effect by the t-statistic value of $>1,96$.
\end{abstract}

Keywords : Evaluation system; HOT-FIT; RISPACS; PLS.

\begin{abstract}
Abstrak
Penerapan teknologi baru seperti Radiology Information System Picture Archiving and Communication ystem (RISPACS) dalam bidang radiologi yang tidak memenuhi harapan pengguna dapat menimbulkan ketidaknyamanan pengguna teknologi yang akan berdampak pada produktivitasnya. Untuk mengantisipasi hal tersebut diperlukan pemahaman tentang faktor-faktor mendasar yang berkontribusi mampu mempengaruhi penerimaan dan keberhasilan dalam penerapan teknologi RISPACS. Penelitian ini bertujuan untuk mengetahui gambaran evaluasi keberhasilan penerapan RISPACS dengan pendekatan model Human Organization Technology (HOT FIT) di Instalasi Radiologi RSUP Sanglah Denpasar. Analisis yang digunakan dalam penelitian ini menggunakan Partial Least Square (PLS) dengan jumlah responden sebanyak 71 petugas radiologi yang menggunakan sistem RISPACS yang diukur. Hasil evaluasi model HOT FIT menunjukkan bahwa keberhasilan penerapan teknologi RISPACS memiliki penilaian positif yang dilihat dari sikap pengguna dalam merespon suatu teknologi RISPACS yang dirasakan sudah sesuai dengan harapan dan kebutuhan operasional pengguna. Variabel kualitas sistem, kualitas informasi, kualitas layanan memiliki pengaruh positif terhadap variabel pengguna sistem dan kepuasan pengguna. Variabel pengguna sistem, kepuasan pengguna, struktur organisasi dan lingkungan organisasi memiliki pengaruh yang positif dan signifikan terhadap net benefit dilihat dari nilai t-statistik $>1,96$.
\end{abstract}

Kata Kunci : Evaluasi Sistem; HOT-FIT; RISPACS; PLS.

*) Penulis korespondensi: vierdalya93@gmail.com 


\section{Pendahuluan}

Kemajuan sistem informasi telah mempengaruhi dan mendorong peningkatan pelayanan kesehatan yang diberikan dalam rangka memenuhi tuntutan masyarakat akan ketepatan dan kecepatan pelayanan yang diberikan oleh rumah sakit. Hal ini didukung dengan adanya kebijakan dari Departemen Kesehatan RI serta menjadi pedoman bagi penyelenggaraan pembangunan kesehatan yang dilaksanakan oleh pemerintah maupun swasta dalam rangka meningkatkan mutu pelayanan kesehatan di rumah sakit, sesuai dengan Peraturan Menteri Kesehatan Republik Indonesia Nomor 1171/MENKES/PER/VI/2011 Pasal 1 Ayat 1 yang menyebutkan bahwa "Setiap rumah sakit wajib melaksanakan Sistem Informasi Rumah Sakit". Namun, pada kenyataannya perkembangan sistem yang ada di rumah sakit belum dapat dikatakan mengalami perkembangan yang cukup baik. Masih terdapat hal yang bersifat operasional dan manajerial yang membuat penerapan sistem informasi pada rumah sakit mengalami hambatan. Oleh karena itu, diperlukan pengelolaan sistem informasi yang baik, yaitu dengan adanya mekanisme kontrol internal dan evaluasi sistem informasi di rumah sakit. Salah satu yang perlu dievaluasi penggunaan sistem informasi ke arah fungsi klinis yang digunakan pada unit radiologi adalah penerapan teknologi baru seperti Radiology Information System Picture Archiving and Communication System (RISPACS).

Radiology Information System (RIS) merupakan suatu sistem yang difungsikan untuk mendukung fungsi operasional atau alur kerja serta fungsi administratif di dalam departemen radiologi (The Royal College of Radiologists. 2008). RIS bukanlah sistem yang berdiri sendiri, namun berinteraksi dengan sistem lainnya yang secara terintegrasi untuk meningkatkan pelaksanaan prosedur kegiatan medis. Salah satunya RIS dapat berinteraksi dengan Sistem Informasi Manajemen Rumah Sakit (SIMRS) dan Picture Archiving and Communication System (PACS) yang merupakan metode komunikasi terkomputerisasi yang mampu menyimpan data hasil gambar citra medis seperti digital radiographic (DR), computed radiographic (CR), computed tomographic (CT SCAN), ultrasoundgraphy (USG), fluoroscopic, magnetic resonance imaging (MRI) dan foto $X$-ray konventional dalam bentuk filmless (Tong et al, 2009). Hasil gambar citra radiologi tersebut memungkinkan untuk dapat dilihat secara virtual dimanapun pada komputer server ataupun komputer personal biasa. PACS memberikan kecepatan waktu respon pembacaan hasil citra oleh dokter radiologi sehingga mampu meningkatkan kualitas pelayanan kesehatan khususnya di instalasi radiologi.

Penerapan RISPACS, kepuasan pengguna, serta kemanfaatan dalam menggunakan sistem tersebut sangat bergantung pada pengetahuan user dalam cara menggunakan RISPACS. Manfaat serta kemudahan dari aplikasi RISPACS dapat dilihat dari kualitas sistem, kualitas informasi dan kualitas layanan yang diberikan pada departemen radiologi. Hal tersebut akan berpengaruh terhadap sikap pengguna yang ingin menerapkan RISPACS dan menerima RISPACS, agar dalam penerapannya dapat bermanfaat sesuai dengan kebutuhan organisasi dan mampu meningkatkan kinerja organisasi.

Evaluasi RISPACS dengan menggunakan model HOT-FIT dinilai dari sisi tiga komponen penting yaitu human, organization dan technology serta kesesuaian hubungan antar komponen yang dapat mempengaruhi kemanfaatan atau net benefit dari RISPACS. Menurut Yusof (2011) komponen human yaitu menilai sistem informasi dari sisi user atau penggunaan sistem serta aspek kepuasan user atau pengguna, komponen organization yaitu struktur organisasi dan lingkungan, serta komponen terakhir yaitu technology dimana komponen ini menilai sistem informasi dari sisi kualitas sistem, kualitas informasi yang diberikan serta kualitas layanan.

Hambatan dalam penerapan RISPACS yang dirasakan pengguna serta sering terjadinya kesalahan dalam menginput data informasi seperti kekeliruan setting system yang menyebabkan adanya data yang tidak sesuai. Untuk meminimalisir hal tersebut perlu adanya evaluasi penerapan RISPACS agar sistem RISPACS dapat memberikan hasil yang tepat sesuai dengan kebutuhan organisasi. Mengingat RISPACS baru diterapkan dalam kurun waktu satu tahun terakhir serta belum pernah terukur hingga saat ini. Perubahan sistem informasi radiologi dari sistem konvensional ke sistem yang baru memerlukan proses transisi, dimana bagi beberapa petugas radiologi mampu menimbulkan rasa ketidaknyamanan dalam proses adaptasi dengan sistem yang baru. Tujuan penelitian ini untuk melihat gambaran hasil evaluasi keberhasilan penerapan RISPACS di instalasi radiologi RSUP Sanglah Denpasar dengan menggunakan model evaluasi Human Organization Technology (HOT FIT) sehingga dapat memberikan rekomendasi terkait pengembangan sistem ke tahap selanjutnya.

\section{Kerangka Teori}

\subsection{RISPACS}

Radiologi Information System (RIS) merupakan suatu sistem yang dirancang untuk mendukung alur kerja operasional serta analisis proses bisnis dalam instalasi radiologi. RIS juga merupakan tempat penyimpanan data pasien serta laporan di instalasi radiologi serta berkontribusi dalam catatan klinis pasien elektronik (The Royal College of Radiologists. 2008).

RIS membantu pengelolaan permintaan pemesanan pemeriksaan, pendaftaran pasien radiologi, pemeriksaan radiologi, pembuatan hasil 
laporan, daftar persiapan pekerjaan, penjadwalan, hasil persetujuan dan sistem manajemen yang termasuk dalam fungsi administrasi dan operasional di instalasi radiologi.

Secara fungsional RIS tidak dapat berdiri sendiri namun terintegrasi dengan sistem lainnya seperti Hospital Information System (HIS) serta Picture Archiving and Communication System (PACS) untuk membantu menyediakan informasi yang diperlukan dalam proses alur kerja dan proses bisnis operasional di instalasi radiologi. RIS harus berkomunikasi dengan PACS, menurut (Dreyer et al, 2006) dengan adanya PACS, gambar radiologi memungkinkan untuk dapat dilihat secara virtual atau elektronik dimanapun pada komputer server ataupun komputer personal biasa serta sebagai yang bertanggungjawab untuk prosedur internal yang dilakukan ke dalam departemen radiologi diantaranya pengambilan, pengolahan dan pengarsipan berkas pencitraan medis. RIS harus mengumpulkan informasi tersebut dengan tepat agar dapat menghasilkan laporan akhir medis untuk setiap pemeriksaan radiologi. Selain itu RIS juga terintegrasi dengan HIS dalam melakukan pengambilan informasi pasien, memperbaharui catatan medis untuk pengujian baru serta proses penagihan biaya yang sesuai dengan tindakan radiologi yang dilakukan.

Secara sederhana RIS merupakan penggerak alur kerja dalam instalasi radiologi. RIS bertanggungjawab dalam proses pemesanan jadwal pemeriksaan, membagikan informasi klinis terkait pemeriksaan radiologi, mempersiapkan daftar kerja (modality) atau worklist serta menyediakan informasi yang dibutuhkan PACS untuk menjalankan perannya. Apabila citra telah diakusisi, PACS akan mengelolanya untuk memastikan tidak ada kesalahan dalam proses penyimpanan, pengambilan, serta pengiriman citra radiologi. Selain itu PACS akan menjamin penyimpanan data citra diagnostik dalam jangka panjang serta dapat digunakan kapan saja secara real time, terutama pada interpretasi citra radiologi. Inti dari PACS yaitu terdiri dari sistem manajemen database relasional (yang digunakan dapat berupa Oracle, MS-SQL, Sybase), media penyimpan pada PACS (yang digunakan seperti RAID, Jukebox), serta software pengendali (image manager), dan antarmuka RIS. Kemudian RIS dan PACS bekerja sama untuk menyediakan informasi yang dibutuhkan oleh dokter radiologi dalam pembacaan hasil pencitraan radiologi. Selain itu RIS juga menyediakan data yang mendukung pembuatan laporan hasil pembacaan yang dilakukan dokter radiologi.

\subsection{Human Organization Technology-FIT (HOT- FIT)}

HOT-FIT merupakan kerangka model evaluasi yang dikembangkan oleh yusof et al. Model ini didasarkan pada penelitian sebelumnya yaitu model yang dikembangkan oleh DeLone and McLean (1992,2004) yaitu IS Success, pada model ini digunakan untuk mengidentifikasi faktor, dimensi, serta ukuran dari kriteria evaluasi sistem yang ingin diukur, selanjutnya model yang dikembangkan oleh Scott Morton (1991) yaitu model IT Organisasi FIT Model, pada model ini digunakan untuk mengidentifikasi konsep serta hubungan pada tiga faktor evaluasi yaitu faktor manusia, organisasi dan teknologi. Kerangka model evaluasi HOT-FIT dikembangkan untuk mengevaluasi Sistem Informasi Kesehatan (SIK) yang dimana pada tiga faktor tersebut dapat diketahui dampak SIK yang dievaluasi dengan melihat keseluruhan dari net benefitnya (Yusof, 2013).

Menurut McKeen dan Guimaraes (1997) sumber daya manusia merupakan faktor penentu dalam kesuksesan penerapan suatu sistem. Selanjutnya menurut Gibson (2012) kesuksesan dalam penerapan sistem informasi dalam suatu organisasi tidak boleh mengabaikan kebutuhan pengguna. Apabila kebutuhan maupun harapan pengguna sistem diabaikan maka dapat mengakibatkan sistem tersebut cenderung kurang produktif dan tidak efisien. Setiap pengguna sistem memiliki pemahaman, perasaan, serta penilaian yang berbeda makna kualitas. Dalam evaluasi sistem model HOT-FIT dampak positif maupun dampak negatif yang dirasakan pengguna dalam penerapan sistem dapat dijadikan ukuran dalam melihat net benefit (Erimalata, 2016).

Berdasarkan hasil analisis tinjauan sistematis yang dilakukan oleh Yusof (2011), diidentifikasi bahwa dimensi pengembangan sistem pada kerangka HOTFIT menunjukkan kesesuaian antara ketiga faktor yaitu manusia, organisasi dan teknologi yang diukur dan dianalisis dengan menggunakan dimensi lainnya diantaranya: kualitas sistem, kualitas informasi, kualitas layanan, pengguna sistem, kepuasan pengguna, struktur organisasi, lingkungan organisasi dan net benefit, sehingga kerangka model evaluasi HOT-FIT dapat dikatakan model evaluasi yang mampu melakukan evaluasi sistem dengan teliti dan sistematis terhadap siklus hidup dari pengembangan sistem apapun.

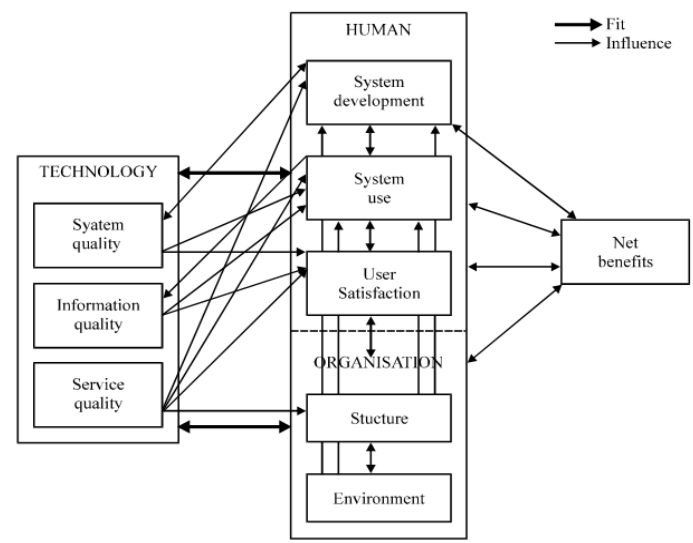

Gambar 1. Model HOT-FIT (Yusof, 2011) 


\subsection{Partial Least Square (PLS)}

Partial Least Square (PLS) merupakan persamaan struktural (SEM) yang berbasis pada komponen atau pada varian. Menurut Sarstedt, et al. (2014) PLS sebagai teknik prediksi model yang mampu menyelesaikan banyak variabel. Partial Least Square (PLS) bersifat predictive model atau permodelan eksplorasi. PLS mampu menghubungkan banyak variabel, dapat diimplementasikan sebagai model regresi, dapat diimplementasikan sebagai model jalur yang menangani jalur kausal yang berhubungan dengan prediktor serta jalur yang menghubungkan prediktor dengan variabel, serta sampel yang digunakan tidak harus besar (Garson. 2016). Menurut Lowry dan Gaskin (2014) PLS juga bersifat robust, yaitu parameter dalam model tidak akan banyak berubah apabila sampel yang baru diambil dari populasi total.

Teknik analisis PLS dilakukan dengan menguji outer model, mengevaluasi goodness of fit pada inner model serta menguji hipotesisnya. Pengujian struktural (inner) model yang digunakan untuk mengetahui pengaruh antar variabel atau korelasi antara konstruk-konstruk yang diukur menggunakan uji t dari PLS. Struktural (inner) model diukur dengan melihat R-Square model yang mampu menunjukkan seberapa besar pengaruh antar variabel pada setiap model. Selanjutnya adalah estimasi koefisien jalur dimana nilai estimasi tersebut digunakan untuk menghubungkan jalur ke dalam model struktural dengan prosedur bootstrapping. (Garson. 2016).

\section{Metode}

Penelitian ini untuk melihat gambaran evaluasi penerapan RISPACS di Instalasi Radiologi RSUP Sanglah Denpasar yakni dengan studi korelasi sajauh mana pengaruh masing-masing konstruk dalam model HOT-FIT dengan variabel endogen yang meliputi penggunaan sistem, kepuasan pengguna, serta variabel eksogen yang meliputi kualitas sistem, kualitas informasi, kualitas layanan, struktur organisasi, lingkungan kerja untuk menilai net benefit dari penerapan RISPACS yang diukur berdasarkan persepsi pengguna. Kuesioner yang digunakan diadaptasi dari model HOT-FIT yang dikembangkan oleh Yusof (2011) yang kemudian disesuaikan dengan tujuan penelitian. Selanjutnya kuesioner diberikan kepada petugas radiologi yang menggunakan RISPACS.

Penelitian ini mengukur tingkat keberhasilan penerapan teknologi menggunakan model HOT-FIT. Sehingga hipotesis yang dikembangkan pada penelitian ini berdasarkan pada Gambar 2 yaitu :

H1 : Variabel kualitas sistem (KS) memiliki pengaruh positif terhadap penggunaan sistem (PS)

H2 : Variabel kualitas sistem (KS) memiliki pengaruh positif terhadap kepuasan pengguna (KP)

H3 : Variabel kualitas informasi (KI) memiliki pengaruh positif terhadap penggunaan sistem (PS)

H4 : Variabel kualitas informasi (KI) memiliki pengaruh positif terhadap kepuasan pengguna (KP)

H5 : Variabel kualitas layanan (KL) memiliki pengaruh positif terhadap penggunaan sistem (PS)

H6 : Variabel kualitas layanan (KL) memiliki pengaruh positif terhadap kepuasan pengguna (KP)

$\mathrm{H} 7 \quad$ : Variabel penggunaan sistem (PS) memiliki pengaruh positif terhadap net benefit (NB)

H8 : Variabel kepuasan pengguna (KP) memiliki pengaruh positif terhadap net benefit (NB)

H9 : Variabel struktur organisasi (SO) memiliki pengaruh positif terhadap net benefit (NB)

H10 : Variabel lingkungan kerja (LK) memiliki pengaruh positif terhadap net benefit (NB)

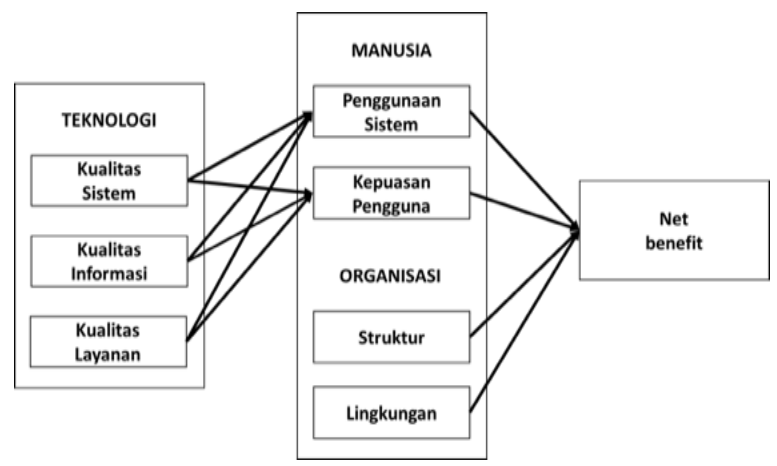

Gambar 2. Model Penelitian HOT-FIT

Jenis penelitian yang akan dilakukan adalah penelitian kuantitatif. Penelitian ini menggunakan teknik sampel jenuh yang terdiri dari keseluruhan petugas radiologi yang menggunakan RISPACS. Sebanyak 71 orang yang terdiri atas radiografer, petugas administrasi radiologi, dokter radiologi, dan dokter residen radiologi. Data dikumpulkan menggunakan kuesioner tertulis dengan sampel yang berpartisipasi secara sukarela dan setiap responden setuju untuk berpartisipasi dalam penelitian ini.

Kuesioner yang digunakan dalam penelitian ini terdiri dari 16 item yang dibagi dalam 2 bagian : a) Karakteristik Demografi, b) Evaluasi model HOTFIT. Bagian kedua dari kuesioner terdiri dari 40 item yang diadaptasi dari model HOT-FIT yang dikembangkan oleh Yusof (2011). Instrumen asli memiliki konsistensi internal rata-rata dimana semua skala pengukuran menunjukkan validitas dan reliabilitas yang tinggi, dengan koefisien cronbach alpha untuk ke delapan item validitas konstruk sangat didukung oleh analisis komponen utama. Uji validitas dilakukan pada 30 petugas radiologi yang menggunakan RISPACS kemudian diuji dengan 
teknik korelasi product moment dengan skor korelasi (r) $\geq 0,361$, sedangkan untuk uji reliabilitas nilai cronbach alpha >0,6. Selanjutnya penelitian ini menggunakan teknik uji coba terpakai dimana indikator-indikator pada instrumen penelitian yang telah valid yang langsung digunakan untuk menguji hipotesis penelitian.

Semua item pada bagian kedua diukur dengan skala likert empat poin yaitu sangat setuju (SS), setuju (S), tidak setuju (TS), sangat tidak setuju (STS) digunakan. Pengolahan dan analisis data menggunakan analisis univariat untuk data demografi dan analisa multivariat menggunakan pendekatan Partial Least Square (PLS) untuk menguji predictive model sebagai model jalur yang menangani jalur kausal yang berhubungan dengan prediktor serta jalur yang menghubungkan prediktor dengan variabel. Hipotesis yang dibangun menggunakan arah two tailed yang artinya hasil nilai t-statistik harus $>1,96$. Tahap analisis data dilakukan dengan beberapa tahapan sebagai berikut : (1) uji validitas dan reliabilitas model; (2) uji hubungan antar konstruk dalam model; (3) menguji konfirmasi model yang terbentuk. Pada penelitian ini telah mendapatkan persetujuan dari Komisi Etik FK Unud/RSUP Sanglah Denpasar dengan nomor 61/UN14.2.2.VII.14/LP/2019 serta dari Komisi Etik Fakultas Kesehatan Masyarakat Universitas Diponegoro dengan nomor 02/EA/KEPK-FKM/2019.

\section{Hasil dan Pembahasan}

Pengambilan data dilakukan dengan pengisian kuesioner yang disebarkan kepada petugas radiologi. Kuesioner yang berhasil dikumpulkan sebanyak 71 kuesioner disesuaikan dengan jumlah sampel yang telah ditentukan sebelumnya yaitu menggunakan teknik sampel jenuh atau total sampling.

Responden dalam penelitian ini sebagian besar berusia lebih dari 25-50 tahun sebesar 77,5\%, sedangkan yang berumur kisaran 50 tahun sebesar $21.1 \%$ dan yang berumur kurang dari 25 tahun sebesar $1.4 \%$. Responden yang berjenis kelamin lakilaki sebanyak 34 orang $(47.9 \%)$, sedangkan yang berjenis kelamin perempuan sebanyak 37 orang $(52.1 \%)$. Berikutnya mengenai lama bekerja, terdapat responden yang bekerja kurang dari lima tahun sebesar $36.6 \%$ sedangkan yang telah bekerja lebih dari lima tahun yaitu sebesar 63.4\%. Responden dilihat dari lama menggunakan sistem RISPACS kurang dari satu tahun sebesar $26.8 \%$ dan yang telah menggunakan RISPACS lebih dari satu tahun sebesar $73.2 \%$. Responden dilihat dari tingkat pendidikannya, dalam penelitian ini responden mengenyam pendidikan di tingkat SMA sebesar $1.4 \%$, tingkat D3 sebesar $38 \%$, tingkat D4/S1 sebesar $12.7 \%$, dan terakhir tingkat S2/dr.Spesialis atau sedang menjalankan spesialis sebesar $47.9 \%$.
Uji validitas dan reliabilitas model menggunakan pengukuran outer model yang berisi penilaian terkait convergent validity, discriminant validity serta composite reliability. Hasil penilaian covergent validity menunjukkan bahwa keseluruhan konstruk pada model HOT-FIT menggambarkan kesesuaian antara indikator dengan variabel laten dengan ukuran validitas paling lemah yang dapat diterima dari loading factor yaitu sebesar 0,5. Hasil penilaian tersebut dapat dilihat pada Tabel 1.

Tabel 1. Outer Loading Model HOT-FIT

\begin{tabular}{|c|c|c|c|}
\hline Variabel & Item & $\begin{array}{c}\text { Outer } \\
\text { Loading }\end{array}$ & Keterangan \\
\hline \multirow{5}{*}{$\begin{array}{l}\text { Kualitas Sistem } \\
\text { (KS) }\end{array}$} & KS1 & 0.575 & valid \\
\hline & KS2 & 0.734 & valid \\
\hline & $\mathrm{KS} 3$ & 0.820 & valid \\
\hline & KS4 & 0.823 & valid \\
\hline & KS5 & 0.736 & valid \\
\hline \multirow{5}{*}{$\begin{array}{l}\text { Kualitas Informasi } \\
\text { (KI) }\end{array}$} & KI1 & 0.826 & valid \\
\hline & KI2 & 0.772 & valid \\
\hline & KI3 & 0.672 & valid \\
\hline & KI4 & 0.702 & valid \\
\hline & KI5 & 0.674 & valid \\
\hline \multirow{4}{*}{$\begin{array}{l}\text { Kualitas Layanan } \\
\text { (KL) }\end{array}$} & KL1 & 0.685 & valid \\
\hline & KL2 & 0.849 & valid \\
\hline & KL3 & 0.794 & valid \\
\hline & KL4 & 0.707 & valid \\
\hline \multirow{5}{*}{$\begin{array}{l}\text { Pengguna Sistem } \\
\text { (PS) }\end{array}$} & PS1 & 0.640 & valid \\
\hline & PS2 & 0.686 & valid \\
\hline & PS3 & 0.781 & valid \\
\hline & PS4 & 0.751 & valid \\
\hline & PS5 & 0.841 & valid \\
\hline Kepuasan & KP1 & 0.578 & valid \\
\hline \multirow[t]{5}{*}{ Pengguna (KP) } & KP2 & 0.631 & valid \\
\hline & KP3 & 0.724 & valid \\
\hline & KP4 & 0.811 & valid \\
\hline & KP5 & 0.824 & valid \\
\hline & KP6 & 0.775 & valid \\
\hline \multirow{5}{*}{$\begin{array}{l}\text { Struktur Organisasi } \\
(\mathrm{SO})\end{array}$} & SO1 & 0.721 & valid \\
\hline & $\mathrm{SO} 2$ & 0.808 & valid \\
\hline & SO3 & 0.758 & valid \\
\hline & SO4 & 0.885 & valid \\
\hline & SO5 & 0.846 & valid \\
\hline \multirow{5}{*}{$\begin{array}{l}\text { Lingkungan Kerja } \\
\text { (LK) }\end{array}$} & LK1 & 0.752 & valid \\
\hline & LK2 & 0.792 & valid \\
\hline & LK3 & 0.734 & valid \\
\hline & LK4 & 0.788 & valid \\
\hline & LK5 & 0.673 & valid \\
\hline \multirow[t]{5}{*}{ Net Benefit (NB) } & NB1 & 0.659 & valid \\
\hline & NB2 & 0.770 & valid \\
\hline & NB3 & 0.876 & valid \\
\hline & NB4 & 0.652 & valid \\
\hline & NB5 & 0.742 & valid \\
\hline
\end{tabular}

Hasil uji discriminant validity menunjukkan nilai loading lebih besar dari nilai setiap indikator pada konstruk dibandingkan dengan nilai loading pada konstruk lainnya sehingga dapat diketahui keseluruhan konstruk pada model HOT-FIT dinyatakan valid.

Selain itu nilai discriminant validity dapat juga dilihat dari nilai AVE yaitu >0,5 yang kemudian dibandingkan dengan nilai akar AVE. Hasil penilaian 
tersebut dapat dilihat pada Tabel 2. Berdasarkan hasil penilaian tersebut diketahui delapan variabel pada model HOT-FIT memiliki nilai AVE diatas 0,5 dan nilai akar AVE yang lebih tinggi dibandingkan dengan korelasi variabel laten sehingga keseluruhan variabel pada model HOT-FIT dapat dikatakan valid.

Tabel 2. Nilai Discriminant Validity Model HOT-FIT dengan AVE

\begin{tabular}{cccc}
\hline Variabel & AVE & $\sqrt{ }$ AVE & Keterangan \\
\hline KS & 0.552 & 0.743 & valid \\
KI & 0.536 & 0.732 & valid \\
KL & 0.580 & 0.762 & valid \\
PS & 0.553 & 0.743 & valid \\
KP & 0.515 & 0.717 & valid \\
SO & 0.649 & 0.806 & valid \\
LK & 0.562 & 0.749 & valid \\
NB & 0.554 & 0.744 & valid \\
\hline
\end{tabular}

Uji reliabilitas model dapat dilihat dari nilai composite reliability dan nilai cronbach alpha pada masing-masing konstruk memiliki nilai diatas 0,7 sehingga dapat dikatakan reliabel.

Tabel 3. Uji Composite Reliability dan Cronbach Alpha model HOT-FIT

\begin{tabular}{cccl}
\hline Var & $\begin{array}{c}\text { Composite } \\
\text { reliability }\end{array}$ & $\begin{array}{c}\text { Cronbach } \\
\text { alpha }\end{array}$ & Ket \\
\hline KS & 0.858 & 0.792 & Reliabel \\
KI & 0.851 & 0.781 & Reliabel \\
KL & 0.846 & 0.755 & Reliabel \\
PS & 0.859 & 0.794 & Reliabel \\
KP & 0.861 & 0.805 & Reliabel \\
SO & 0.902 & 0.863 & Reliabel \\
LK & 0.864 & 0.804 & Reliabel \\
NB & 0.860 & 0.794 & Reliabel \\
\hline
\end{tabular}

Hasil uji composite reliability dan nilai cronbach alpha pada model HOT-FIT yang dilihat pada Tabel 3 dapat dikatakan reliabel yaitu keseluruhan nilai masing-masing konstruk diatas nilai 0,7. Selanjutnya mengukur kesesuaian model, dalam PLS menggunakan structural (inner) model untuk memprediksi adanya hubungan kausalitas antar variabel. Inner model diukur dengan melihat nilai latent variable correlations dengan $\mathrm{r}>0,05$, path coefficients apabila $\mathrm{r}$ valid, maka path coefficients juga signifikan, serta R-square melihat keragaman konstruk atau variabel eksogen secara keseluruhan.

Nilai R-square digunakan untuk menjelaskan hubungan atau pengaruh dari variabel eksogen terhadap variabel endogen. Pengujian terhadap model struktural dapat dilihat dari nilai R-square dimana merupakan uji goodness of fit model pada setiap variabel yaitu berlaku sebagai kuatnya prediksi dari model struktural. Hasil penilaian $\mathrm{R}$-square dapat dilihat pada Tabel 4.
Tabel 4. Nilai R-square model HOT-FIT

\begin{tabular}{lc}
\hline \multicolumn{1}{c}{ Variabel } & R-square \\
\hline Kualitas Sistem (KS) & \\
Kualitas Informasi (KI) & \\
Kualitas Layanan (KL) & \\
Pengguna Sistem (PS) & 0.896505 \\
Kepuasan Pengguna (KP) & 0.885422 \\
Struktur Organisasi (SO) & \\
Lingkungan Kerja (LK) & \\
Net Benefit (NB) & 0.956036 \\
\hline
\end{tabular}

Untuk mengukur nilai signifikansi pada evaluasi model dilihat dari nilai t-statistik > t-tabel (t-tabel sebesar 1,96) (Tabel 5). Hipotesis yang dibangun pada penelitian ini menggunakan arah two tailed yang artinya hasil nilai t-statistik harus $>1,96$. Berikut ini hasil evaluasi model struktural dari hasil Bootstapping Report dimana keseluruhan model jalur memiliki hasil positif dan signifikan memiliki hubungan.

Tabel 5. Uji Path Coefficients Model HOT-FIT

\begin{tabular}{|c|c|c|c|}
\hline $\begin{array}{c}\text { Diagram } \\
\text { Jalur }\end{array}$ & $\begin{array}{c}\text { Original } \\
\text { Sample }\end{array}$ & $\begin{array}{c}\mathrm{t}- \\
\text { statistik }\end{array}$ & Keterangan \\
\hline $\mathrm{KP} \rightarrow \mathrm{NB}$ & 0.311 & 5.945 & $\begin{array}{c}\text { Positif dan } \\
\text { signifikan }\end{array}$ \\
\hline $\mathrm{KI} \rightarrow \mathrm{KP}$ & 0.357 & 5.071 & $\begin{array}{c}\text { Positif dan } \\
\text { signifikan }\end{array}$ \\
\hline $\mathrm{KI} \rightarrow \mathrm{PS}$ & 0.256 & 6.515 & $\begin{array}{c}\text { Positif dan } \\
\text { signifikan }\end{array}$ \\
\hline $\mathrm{KL} \rightarrow \mathrm{KP}$ & 0.491 & 8.875 & $\begin{array}{c}\text { Positif dan } \\
\text { signifikan }\end{array}$ \\
\hline $\mathrm{KL} \rightarrow \mathrm{PS}$ & 0.211 & 3.404 & $\begin{array}{c}\text { Positif dan } \\
\text { signifikan }\end{array}$ \\
\hline $\mathrm{KS} \rightarrow \mathrm{KP}$ & 0.097 & 3.808 & $\begin{array}{c}\text { Positif dan } \\
\text { signifikan }\end{array}$ \\
\hline $\mathrm{KS} \rightarrow \mathrm{PS}$ & 0.106 & 2.189 & $\begin{array}{c}\text { Positif dan } \\
\text { signifikan }\end{array}$ \\
\hline $\mathrm{LK} \rightarrow \mathrm{NB}$ & 0.407 & 5.325 & $\begin{array}{c}\text { Positif dan } \\
\text { signifikan }\end{array}$ \\
\hline $\mathrm{PS} \rightarrow \mathrm{NB}$ & 0.239 & 5.400 & $\begin{array}{c}\text { Positif dan } \\
\text { signifikan }\end{array}$ \\
\hline $\mathrm{SO} \rightarrow \mathrm{NB}$ & 0.379 & 6.935 & $\begin{array}{c}\text { Positif dan } \\
\text { signifikan }\end{array}$ \\
\hline
\end{tabular}

Hasil uji kesesuaian model dari indikatorindikator terhadap variabel dapat dilihat pada Gambar 3 yang dilengkapi dengan nilai outer loading, nilai Rsquare dan nilai total effect. Output outer loadings diperoleh dari PLS Algorithm Report pada software SmartPLS. Dari Gambar 3 tersebut dapat diketahui keseluruhan skor tidak ada dibawah 0,5, sehingga tidak ada indikator yang harus dikeluarkan dari model jalur. 


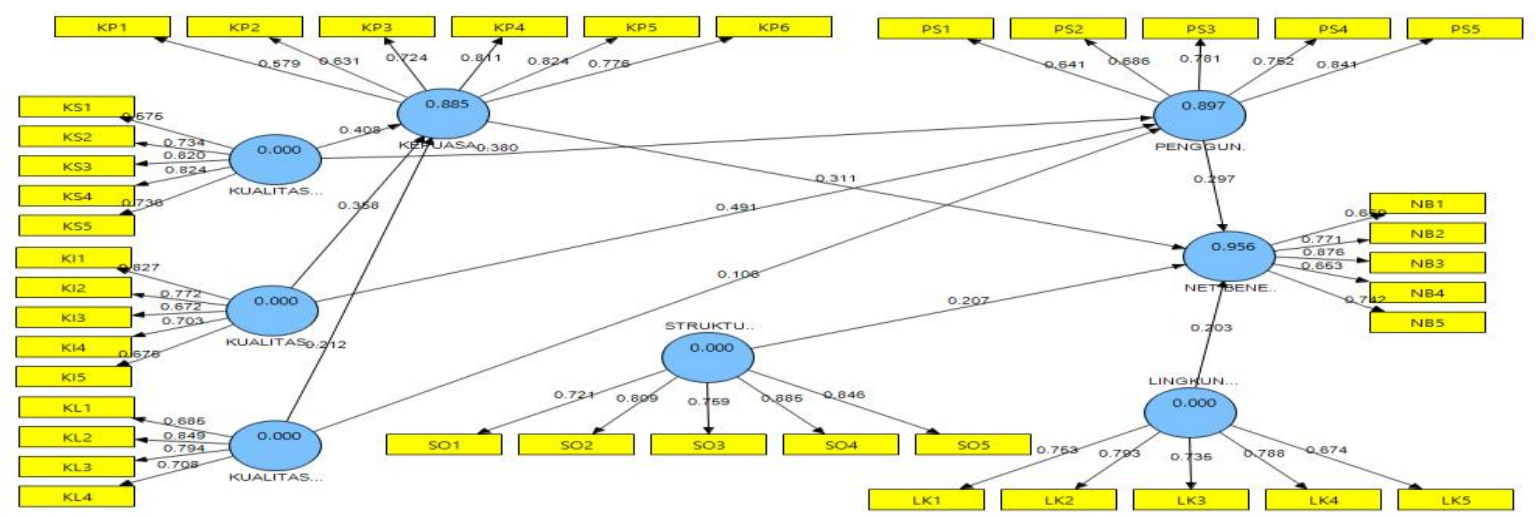

Gambar 3. Output Diagram Jalur Model HOT-FIT

Hasil penilaian model HOT-FIT dimana keseluruhan hipotesis dapat diterima yaitu dengan nilai t-statistik $>1,96$. Salah satu ukuran kesuksesan pada implementasi sebuah sistem dilihat dari kepuasan pengguna. Menurut (Sutardji et al, 2006) kepuasan diartikan sebagai suatu keadaan dari dalam diri individu maupun kelompok yang berhasil mendapatkan sesuatu yang diinginkan dan dibutuhkan. Pengguna merasakan manfaat dari penggunaan RISPACS yang dilihat dari komponen teknologi yang terdiri dari kualitas sistem, kualitas informasi dan kualitas layanan yang memiliki pengaruh positif terhadap komponen manusia yang terdiri dari pengguna sistem serta kepuasan pengguna. Hasil tersebut mengkonfirmasi teori yang dikemukakan oleh Davis (1989) yaitu kualitas sistem yang dilihat sebagai aspek kemudahan dan aspek kebermanfaatan. Semakin tinggi kualitas sistem yang dihasilkan maka semakin tinggi tingkat penggunaan sistem yang dirasakan mudah untuk digunakan serta bermanfaat bagi pengguna. Sedangkan untuk kualitas informasi menurut DeLone McLean (2003) merupakan faktor yang berpengaruh positif dalam meningkatkan niat untuk menggunakan teknologi.

Komponen manusia juga memiliki pengaruh positif terhadap net benefit. Sedangkan pada komponen organisasi yang terdiri dari struktur organisasi dan lingkungan kerja memiliki pengaruh positif terhadap net benefit. Ini dikarenakan pengguna merasakan sistem RISPACS mudah untuk dipahami dan digunakan sehingga dengan kualitas sistem yang baik mampu membantu pengguna dalam menyelesaikan pekerjaannya dengan harapan sistem RISPACS dapat memberikan informasi yang dibutuhkan dengan kualitas yang baik pula. Sedangkan kualitas layanan yang diberikan oleh pihak pengembang semakin tinggi maka semakin tinggi pula tingkat penggunaan sistem serta kepuasan yang dirasakan oleh pengguna yang dilihat dari harapan pengguna dapat terpenuhi oleh pihak pengembang. Menurut (Sekarsari, et al 2017) net benefit dapat dirasakan karena seluruh petugas radiologi memiliki niat untuk menggunakan RISPACS yang didukung oleh pihak pimpinan rumah sakit dengan sarana prasarana yang memadai serta berbagai kualitas yang disediakan oleh sistem RISPACS. Dengan adanya dukungan dari struktur organisasi dapat dilakukan inovasi atau pengembangan lebih lanjut terkait pengambilan keputusan agar sistem RISPACS dapat sesuai dengan harapan pengguna dan kebutuhan organisasi. Sedangkan lingkungan kerja yang dilihat dari adanya dukungan rekan kerja, dukungan pimpinan rumah sakit dan komunikasi yang efektif dimana melibatkan peran serta keahlian dari petugas radiologi diharapkan dapat membantu dalam meningkatkan produktifitas pelayanan radiologi.

Keberhasilan penerapan RISPACS diketahui mampu meningkatkan mutu rumah sakit dengan mempercepat pelayanan di instalasi radiologi. Hasil penelitian sebelumnya diketahui perbandingan lama waktu tunggu pelayanan radiologi sebelum dan sesudah menggunakan RISPACS terjadi penurunan hingga $61 \%$ yaitu dari 135,4 menjadi 52,8 dilihat dari rata-rata waktu pelayanan per hari (menit). Penerapan RISPACS mampu mempersingkat alur pelayanan pasien di instalasi radiologi, mempercepat proses penanganan pasien, mampu mengurangi penggunaan kertas dan CD yang terbuang yang digunakan untuk pengarsipan hasil citra medis sehingga membantu dokter radiologi dalam merawat, mendiagnosa, serta memberikan penanganan medis ke tahap selanjutnya. Dengan demikian evaluasi keberhasilan penerapan RISPACS dapat dikatakan telah sesuai dengan harapan dan manfaat yang dirasakan oleh pengguna. Namun, masih diperlukan pemberian pelatihan penggunaan RISPACS terkait dengan perkembangan teknologi yang terus berkembang serta diharapkan feedback dari pengguna RISPACS, dilihat dari kualitas sistem serta kualitas informasi yang diberikan oleh RISPACS sebagai bahan pertimbangan dalam pengembangan RISPACS dimasa mendatang.

\section{Kesimpulan}

Penelitian ini menunjukkan bahwa keberhasilan penerapan teknologi RISPACS memiliki penilaian 
positif dilihat dari sikap pengguna dalam merespon suatu teknologi RISPACS. Ini dikarenakan RISPACS dirasakan memiliki kesesuaian dengan kebutuhan operasional yang dilaksanakan oleh instalasi radiologi RSUP Sanglah Denpasar serta sesuai dengan kondisi lingkungan kerja dan situasi sosial pada saat ini. Hal ini dibuktikan dengan keseluruhan hipotesis pada model HOT-FIT memiliki pengaruh positif dan signifikan.

Untuk penelitian selanjutnya diharapkan mampu mengukur net benefit dengan pengukuran yang lebih luas dan manfaat yang strategik yang didapatkan oleh organisasi seperti manfaat keuntungan dari investasi yang diperoleh dari penerapan sistem RISPACS serta keuntungan kompetitif berupa hubungan dengan pasien.

\section{Ucapan Terima Kasih}

Terima kasih kepada RSUP Sanglah Denpasar yang telah memberikan ijin penelitian dan data yang diperlukan, serta terima kasih kepada Program Studi Magister Kesehatan Masyarakat, Fakultas Kesehatan Masyarakat Universitas Diponegoro Semarang yang telah mendukung terselesaikannya penelitian ini.

\section{Daftar Pustaka}

Carison, K.S. Tong, Eric, T.T. Wong, 2009. Governance of Picture Archiving and Communications Systems: Data Security and Quality Management of Filmless Radiology. Hershey: Medical Information Science Reference; New York.

Davis, F.D., 1989. Perceived Usefulness, Perceived Ease of Use, and User Acceptance of Information Technology. MIS Q;13(3):319

DeLone, W.H., McLean, E.R., 1992. Information Systems Success: The Quest for the Dependent Variable :3(1):60-95.

DeLone and McLean, 2003. Model of Information Systems Success: A Ten-Year Update. J Manag Inf Syst ;19(4):9-30.

Erimalata, S., 2016. Pendekatan Hot-Fit Framework dalam Generalized Structural Component Analysis pada Sistem Informasi Manajemen Barang Milik Daerah: Sebuah Pengujian Efek Resiprokal. J Akunt Dan Investasi. Program Magister Akuntansi, Universitas Mataram; 14157

Garson, G.D., 2016. Partial Least Squares. Statistical Publishing Associates. Asheboro, NC 27205 USA ;262

Gibson, J., 2012. Organizations: Behavior, Structure, Processes; 642.
Instalasi Radiologi RSUP Sanglah Denpasar, 2018. Mempercepat Waktu Pelayanan di Instalasi Radiologi Central RSUP Sanglah dengan Pengembangan dan Integrasi PACS-RIS. Bali.

Jogiyanto, H., 2008. Metode Penelitian Sistem Informasi: Pedoman dan Contoh Melakukan Penelitian di Bidang Sistem Teknologi Informasi. Yogyakarta: CV. Andi Offset.

Keith, J., Dreyer, David, S., Hirschorn, Thrall, J.H., Mehta, A., 2006. PACS: A Guide to the Digital Revolution. Second. New York: Springer Science+Business Media, Inc.

Lowry, P.B and Gaskin, J., 2014. Partial Least Squares (PLS) Structural Equation Modeling (SEM) for Building and Testing Behavioral Causal Theory: When to Choose it and How to Use it. IEEE Transaction on Professional Communication, Volume: 57,Issue:2,123-146.

McKeen, J.D., Guimaraes, T., 1997. Successful Strategies for User Participation in Systems Development. J Manag Inf Syst.;19(4): 9-30.

Pemerintah Indonesia, 2011. Peraturan Menteri Kesehatan Republik Indonesia Nomor 1171/MENKES/PER/VI/2011 Tentang Sistem Informasi Rumah Sakit. Jakarta.

Sarstedt, M., Ringle, C.M., Smith, D., Reams, R., 2014. Partial Least Square Structural Equation Modeling (PLS-SEM): A Usseful Tool for Family Business Researchers. Journal of Family Business Strategy, Volume 5, Issue 1, 105-115.

Sekarsari, I., Nugroho, E., Ferdiana, R., 2017. Evaluasi Implementasi Sistem Informasi dan Manajemen Objek Pajak (SISMIOP) pada Badan Keuangan dan Aset Daerah Kabupaten Bantul ;28

Sutardji, 2006., MIS. Analisis Beberapa Faktor yang Berpengaruh Pada Kepuasan Pengguna Perpustakaan: Studi kasus di Perpustakaan Balai Penelitian Tanaman Kacang-kacangan dan Umbiumbian. Perpustakaan Pertanian ;15

The Royal College of Radiologists. 2008. Radiology information systems. The Royal College of Radiologists: London.

Venkatesh, V., Davis, F.D., 2000. A Theoretical Extension of the Technology Acceptance Model: Four Longitudinal Field Studies. Manag Sci ;46(2):186-204.

Yusof, M.M., 2009. HOT-fit evaluation framework: Validation using case studies and qualitative systematic review in health information systems evaluation adoption:359-65. N 4th ICIW 2009 Curran Assoc Inc.

Yusof, M.M, Yusuff, A.Y.A., 2013. Evaluating Egovernment system effectiveness using an integrated socio-technical and fit approach ;12(5):13. Inf. Technol J. 